\title{
Preferences of eligible women from an Indian medical college hospital for adapting contraceptives
}

\author{
Sandhya Gadre ${ }^{*}$, Abhishek Gadre ${ }^{2}$ \\ ${ }^{1}$ Department of Obstetrics \& Gynaecology, Chirayu Medical College, Bhopal, Madhya Pradesh, India \\ ${ }^{2}$ Department of Internal Medicine, Cleveland Clinic, Ohio, USA
}

Received: 29 November 2015

Accepted: 12 December 2015

\author{
*Correspondence: \\ Dr. Sandhya Gadre, \\ E-mail: gadre.sandhya@gmail.com
}

Copyright: (c) the author(s), publisher and licensee Medip Academy. This is an open-access article distributed under the terms of the Creative Commons Attribution Non-Commercial License, which permits unrestricted non-commercial use, distribution, and reproduction in any medium, provided the original work is properly cited.

\begin{abstract}
Background: Indian women prefer to avoid unwanted pregnancy, but do not practice contraception adequately. After completing their family size, they are more concerned about terminating their fertility, rather than spacing the births. The main aim and objective of the study is to find out preferences for (a) Regularity if any, of barrier contraceptive usage (b) Use of any contraception at zero gravidity (c) The prevalence of temporary \& permanent contraception (d) Prior practice of any temporary contraception before opting for tubectomy (e) Acceptance of male sterilization.

Methods: The study was conducted at Obstetrics \& Gynaecology department, Chirayu Medical College and Hospital, Bhopal, India. Women in reproductive age group, whether tubectomized or not \& postmenopausal women, attending OPD, admitted or those working at the hospital were included. They were given a prestructured, pretested questionnaire. Sociodemographic details, reproductive \& contraception details recorded. Analyzed as per the demands of the study objectives.

Results: From total 267 study subjects, $81 \%$ were practicing contraception. 103 temporary and 113 had sterilization done. Only $42 \%$ were using barrier contraceptive effectively.46\% of the temporary contraceptive users discontinued. There was no significant difference between temporary and permanent method users. $97 \%$ did not use any contraception at zero gravidity. $69 \%$ of the sterilized population never used any contraception before they underwent sterilization. There was only one vasectomy in 267 study subjects.

Conclusions: The contraceptive methods are poorly practiced. The users do not use any temporary contraception effectively \& adequately. A negligible percentage of eligible women practice contraception before first pregnancy. Very few women practice temporary methods any time before they get sterilization done. Overall, the concept of spacing is lacking. Women are more inclined towards permanent methods. Male sterilization is very rarely chosen by the couples.
\end{abstract}

Keywords: Temporary contraception, Permanent contraception, Sterilization, Zero gravidity

\section{INTRODUCTION}

India's population growth rate is $1.74 \%$. The total fertility rate is $2.85 \%$. Every fifth birth in the world is an Indian and $50 \%$ of Indian population are of reproductive age. ${ }^{1}$

Contraceptive advice is a component of good preventive health care. There are nearly 40 million women in India who would prefer to avoid becoming pregnant but not practicing contraception. ${ }^{2}$ In India, women have no role to play or allowed to play very limited role in making of reproductive decisions. ${ }^{3}$

The women after completing their family size are more concerned about terminating their fertility, rather than spacing the births. Most of them do not practice contraception before they undergo sterilization. ${ }^{4}$ 
This study is planned to assess the preferences of the women from a Medical College Hospital; in reproductive age group for adapting contraception \& their choices regarding the method for the same.

The main aim and objectives of study is to find out;

1. Regularity if any, of barrier contraceptive usage.

2. Use of any contraception at zero gravidity.

3. The prevalence of temporary and permanent contraception.

4. Prior practice of any temporary contraception before opting for tubectomy.

5. Acceptance of male sterilization.

\section{METHODS}

The study was conducted at department of Obstetrics \& Gynaecology, Chirayu Medical College, Bhopal, India on the subjects included in the inclusion criteria. The information required was obtained in the form of response to pre-structured semi-open ended questionnaire. The questionnaire included demographic details, obstetric carrier, use of contraception, the method used, usage of IUCD, duration for continuation, discontinuation if any, the causes for the same. History of permanent contraception was asked. Pilot testing was done, necessary amendments were implicated. Ethical requirements of informed verbal consent and confidentiality were ensured. The data was analyzed from the point of view of the aims and objectives mentioned.

Study design: A cross-sectional mixed study

Study settings: Department of Obstetrics \& Gynaecology, Chirayu Medical College \& Hospital, Bhopal, India.

Study subjects: Those fulfilling inclusion criteria $(\mathrm{n}=$ 267).

Statistical analysis: Statistical analysis was done by chi- square test of significance, proportions and percentages.

The data was collected from the proforma of the subjects.

\section{Inclusion criteria}

1. Married women of reproductive age group having minimum one childbirth attending gynaecology OPD \& those admitted in the department who were
a. Reporting for MTP
b. Pregnant at present, during antenatal visits to be counseled for post-delivery contraception.
c. Admitted for delivery.
d. Immediate postpartum and post abortal
e. Lactating mothers

f. Having completed families, not recently delivered or aborted, not using contraception.

g. Not completed families, not using contraception for spacing

h. Using other methods of contraception.

2. Women who had undergone tubal ligation were interviewed about any contraception in the past.

3. Women who had menopause were interviewed whether they had accepted any contraceptive, temporary or permanent in the past.

4. Married nursing staff, lab technicians, clerical staff, attendants working in the hospital, who belonged to reproductive age group, with parameters a, b, c, $\mathrm{d}, \mathrm{e}, \mathrm{f}, \mathrm{g}, \mathrm{h}$ and 2,3 .

\section{Exclusion criteria}

1. H/o irregular bleeding pv, menorrhagia, PID, valvular heart diseases

2. Prepubertal girls.

Approval obtained from Research Committee of the Institution

\section{RESULTS}

This retrospective study was done on 267 women. The sociodemographic features of women under study are depicted in Table no. 1. Among them $31.84 \%$ women had one living child, $31.09 \%$ had 2 living children, $22.10 \%$ had 3 living issues. Mean parity was 2.49 with $\mathrm{SD} \pm 1.57$. $20.60 \%$ subjects had one abortion, $5.24 \%$ had 2 abortions, $1.12 \%$ had 3 abortions and $1.12 \%$ had 4 abortions whereas $0.76 \%$ had 6 abortions. Out of 267 subjects, 216 women (81\%) had used contraception; $51(19 \%)$ did not. Out of these, 113 were using temporary methods and 103 had undergone for permanent contraception.

There were 113 women using temporary contraception. Condom was utilized by maximum couples $47 \%$ followed by OCPs $21 \%$ and IUCD by $19 \%$. Majority of women had used OCP for 1 to 5 cycles, only few used OCPs continuously for 3 years of spacing. Out of the IUCD users, only 7 women are still continuing with their IUCDs as shown in Figure 1.

In our study, 53 were considered as barrier contraceptive users. This was analyzed by using Likert's scale and it was found that only $42 \%$ partners used it effectively (at every sexual exposure), 68\% users used it irregularly and insufficiently as shown in Table 2 .

Out of 113 users, 52 women $(46.01 \%)$ discontinued temporary contraceptives without any reason $30.76 \%$. The other reasons like trivial trouble $25 \%$, menstrual problems and wanted pregnancy $19.23 \%$, husband unwilling 3.84\% and TT $1.92 \%$ as seen in Figure 2. 
Table 1: Sociodemographic characters of the women under study.

\begin{tabular}{|c|c|c|}
\hline Characteristics & $\begin{array}{l}\text { No. of cases } \\
(N=267)\end{array}$ & $\begin{array}{l}\text { Percentage } \\
(\mathbf{1 0 0 \% )}\end{array}$ \\
\hline \multicolumn{3}{|l|}{ Residence } \\
\hline Rural & 52 & 19.48 \\
\hline Urban & 215 & 80.52 \\
\hline \multicolumn{3}{|c|}{ Age Distribution (Mean age 33.5 years, $S D \pm 10.1$ ) } \\
\hline $20-29$ & 110 & 41.20 \\
\hline $30-39$ & 83 & 31.09 \\
\hline $40-49$ & 46 & 17.23 \\
\hline $50-59$ & 23 & 8.61 \\
\hline $60-69$ & 05 & 1.87 \\
\hline \multicolumn{3}{|l|}{ Religion } \\
\hline Hindu & 243 & 91.01 \\
\hline Muslim & 22 & 08.24 \\
\hline Christian & 02 & 00.75 \\
\hline \multicolumn{3}{|l|}{ Education Level } \\
\hline Uneducated & 65 & 24.34 \\
\hline Primary & 40 & 14.98 \\
\hline Middle & 85 & 31.84 \\
\hline Secondary & 08 & 03.00 \\
\hline Higher secondary & 04 & 01.50 \\
\hline Graduate & 45 & 16.85 \\
\hline Postgraduate & 20 & 07.49 \\
\hline \multicolumn{3}{|l|}{ Income Group } \\
\hline BPL card holder & 157 & 58.80 \\
\hline Non holders of BPL card & 110 & 41.19 \\
\hline \multicolumn{3}{|l|}{ Occupation } \\
\hline Majority were & 157 & 58.80 \\
\hline
\end{tabular}

Table 2: The regularity of condom use.

\begin{tabular}{|lll|}
\hline Frequency & Users $\mathbf{n = 5 3}$ & $\mathbf{1 0 0 \%}$ \\
\hline Always & 22 & 42.00 \\
\hline Most Often & 03 & 05.66 \\
\hline Often & 04 & 07.54 \\
\hline Sometimes & 06 & 11.32 \\
\hline Very Rarely & 18 & 33.96 \\
\hline
\end{tabular}

The difference between temporary \& permanent contraception was statistically not significant, $\mathrm{p}=0.82$. $51(19.10 \%)$ subjects were nonusers of contraception as shown in Table 3. $96.62 \%$ have none used any contraceptive at zero gravidity, $2.62 \%$ used condoms as seen in Figure 3.

The mean interval between last childbirth and tubectomy was 1.32 years as shown in Table 4 . Out of 103 women who had underwent sterilization (102 tubectomies + 1 vasectomy), only $32(31.06 \%)$ had prior history of using temporary contraception. 71 women did not use any temporary contraception before they opted for sterilization (Figure 4). Only one husband had vasectomy done as shown in Figure 5.

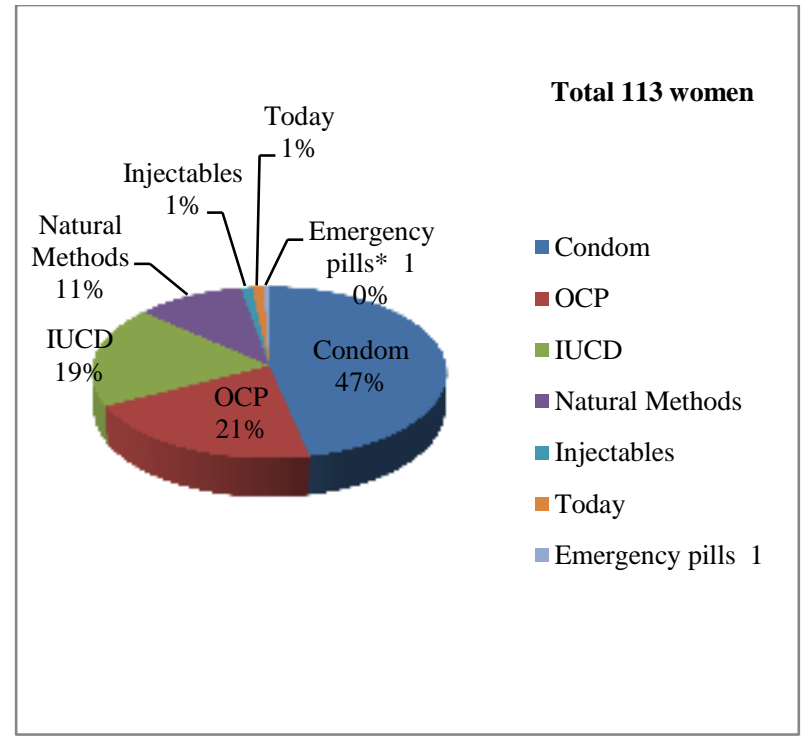

Figure 1: Methods used for temporary contraception.

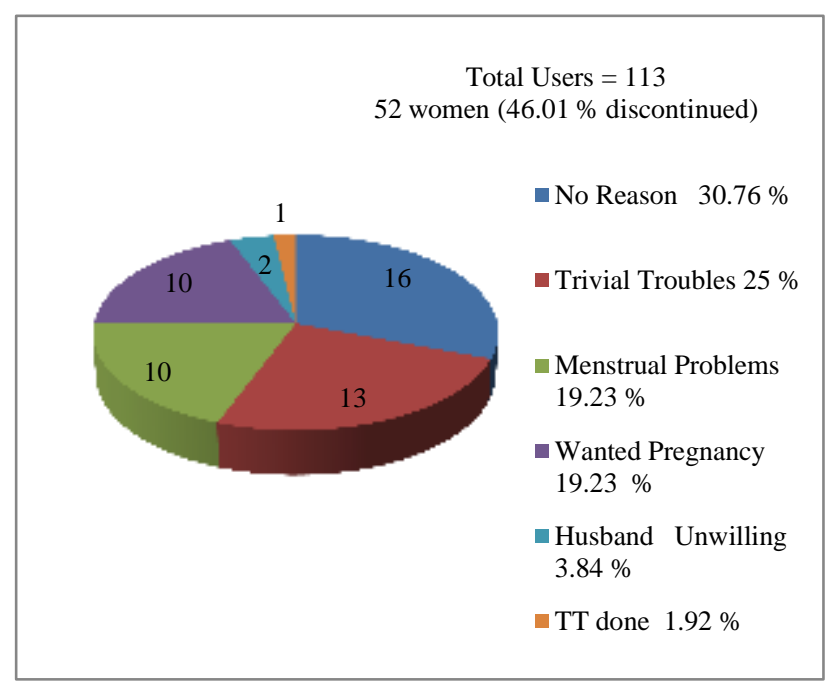

Figure 2: Causes for discontinuation of temporary contraceptives.

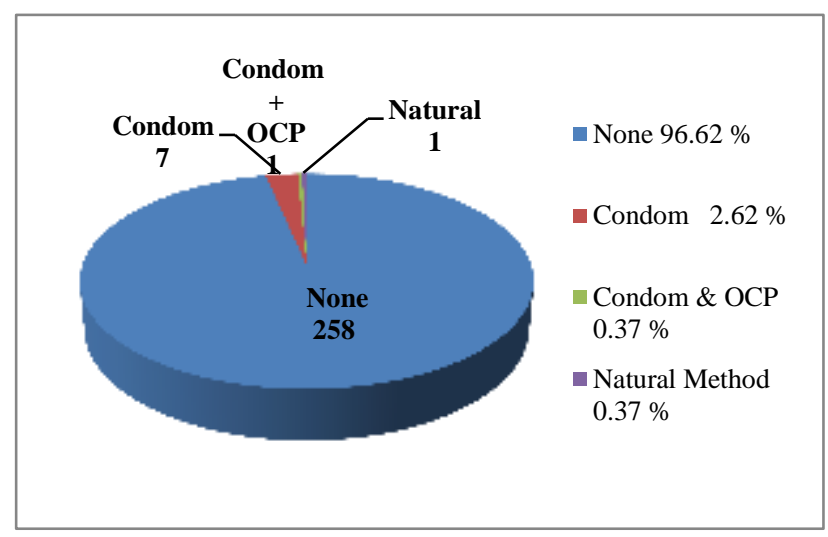

Figure 3: Contraceptive use at zero gravidity. 
Table 3: Prevalence of contraceptive users temporary Vs permanent (Total no. of Subjects using contraception $=216$ ) .

\begin{tabular}{|lccccc|} 
Contraception & $\mathbf{N}$ & $\%$ & $\begin{array}{l}\text { Chi Square } \\
\text { Value }\end{array}$ & $\begin{array}{l}\text { p } \\
\text { value }\end{array}$ \\
\cline { 1 - 2 } Temporary & 113 & 52.31 & & \multirow{2}{*}{0.03} & 0.82 \\
\cline { 1 - 2 } Permanent & 103 & 47.68 & & \\
\cline { 1 - 3 } Total & 216 & 100 & & \\
\hline
\end{tabular}

N= No. of cases

Table 4: Interval between last childbirth and sterilization.

\begin{tabular}{|c|c|c|}
\hline Interval & Number & Mean Interval \\
\hline $\begin{array}{l}\text { Zero Interval (PTT, CS } \\
\text { with TT)* }\end{array}$ & 23 & \multirow{9}{*}{1.32 years } \\
\hline 15 Days & 02 & \\
\hline 3 Months & 13 & \\
\hline 6 Months & 15 & \\
\hline 1 Year & 25 & \\
\hline 2 Years & 17 & \\
\hline 3 Years & 06 & \\
\hline 6 Years & 01 & \\
\hline 7 Years & 01 & \\
\hline
\end{tabular}

Table 5: Source of contraception information.

\begin{tabular}{|c|c|c|c|c|c|}
\hline \multirow[t]{2}{*}{ Source } & \multicolumn{2}{|c|}{$\begin{array}{l}\text { Temporary } \\
\mathbf{N}=\mathbf{1 1 3}\end{array}$} & \multicolumn{2}{|c|}{$\begin{array}{l}\text { Permanen } \\
\mathrm{t} \\
\mathrm{N}=103\end{array}$} & \multirow[t]{2}{*}{$\begin{array}{l}\mathbf{Z} \text { Test } \\
\mathbf{P} \\
\text { value }\end{array}$} \\
\hline & No. & $\%$ & No. & $\%$ & \\
\hline Self-Knowledge & 48 & 42.47 & 49 & $\begin{array}{l}47.5 \\
7\end{array}$ & 0.45 \\
\hline Medical Person & 42 & 37.16 & 20 & 19.4 & 0.003 \\
\hline $\begin{array}{l}\text { Paramedical } \\
\text { Person }\end{array}$ & 13 & 11.50 & 34 & 33.0 & 0.0001 \\
\hline $\begin{array}{l}\text { Relatives/ } \\
\text { Friends }\end{array}$ & 09 & 07.96 & Nil & - & - \\
\hline $\begin{array}{l}\text { Television/ } \\
\text { Print Media }\end{array}$ & 01 & 00.88 & Nil & - & - \\
\hline
\end{tabular}

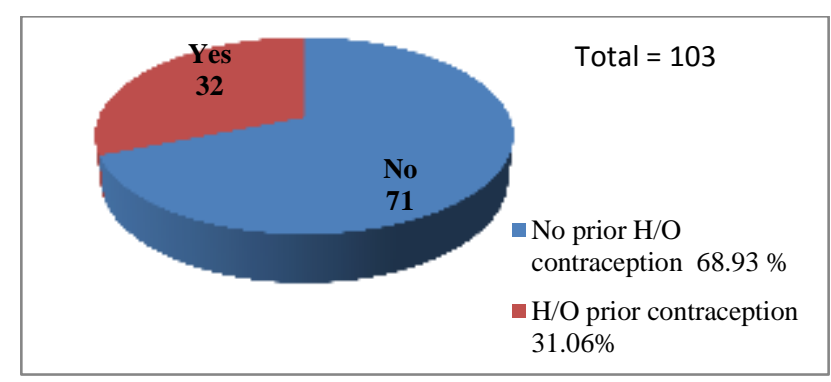

$*(\mathrm{H} / \mathrm{O}=$ History of $)$

Figure 4: Prior temporary contraception before sterilization.

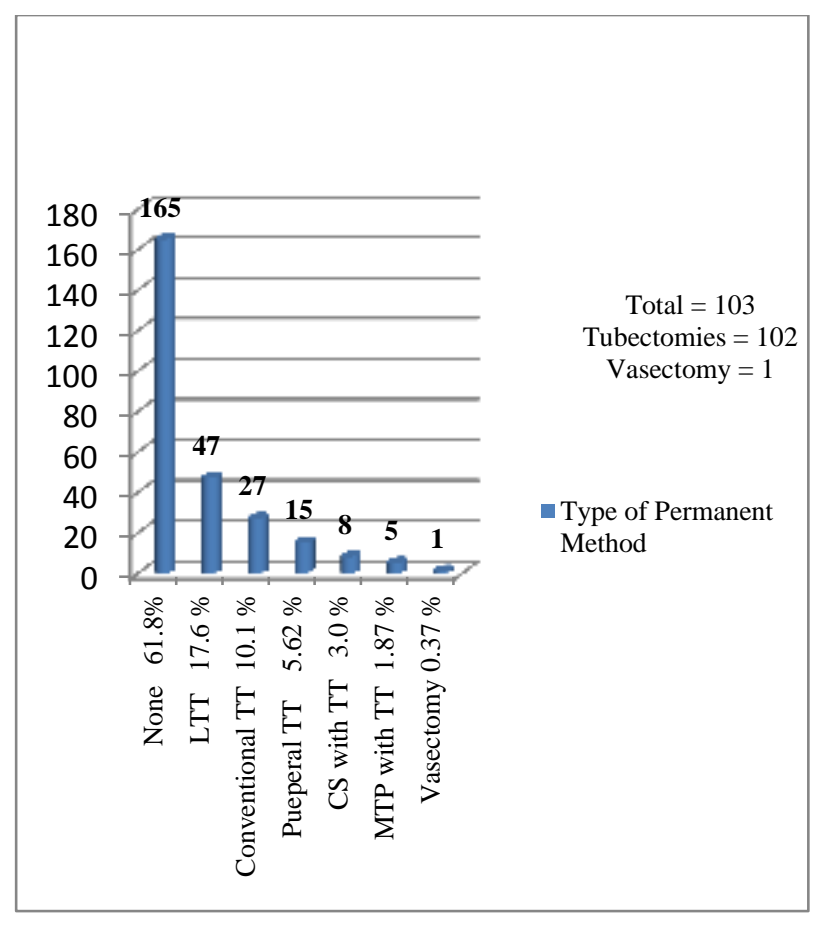

Figure 5: Type of permanent methods.

\section{DISCUSSION}

In India there is lack of awareness of contraception in general which is not satisfactory even when they are aware, it is being underutilized. ${ }^{5}$ Most of the currently married women are exposed to their first cohabitation at very early age and they have their desired number of children within a short span of time.

According to National Family Health Survey, 56\% of married Indian women are using contraception. ${ }^{6}$ Renjhen et al quoted contraceptive users to be $55.2 \%{ }^{7}$ The observations of our study show that $80.89 \%$ of the study subjects were using contraception. Although this figure appears very attractive in the first look, but on further exploring the details, it was observed that contraception was improperly $\&$ inadequately practiced.

Temporary contraceptive users were $52 \%$. Barrier contraception was used by the majority $19.85 \%$ out of 267, followed by OCP $7.85 \%$ and IUCD $7 \%$. This finding is not consistent with those of other studies which have obtained figures of $37.9 \%$ for OCP, $31 \%$ for barrier and $24 \%$ for IUCD. ${ }^{7,8}$

Although all these were labeled as contraceptive users, they were not being used effectively. Only $42 \%$ of the condom users were using it at every sexual exposure, rest of them was using it ineffectively $\&$ inadequately.

Even the benefit of OCPs was not picked up properly by majority of the women. Very few used them continuously for 3 years of spacing. Out of the IUCD users only 7 women are still continuing with their 
IUCDs. Rest all have got it removed due to some or the other reason.

Emergency contraception which is not a method for regular use was used as a regular method of contraception by one study subject.

This suggests that although they want to avoid or postpone pregnancy, they do not opt for contraception in a way it should be used. On the contrary these couples had a false sense of security from unwanted pregnancy.

Even if they are using it ineffectively, they do not continue with it for long. Most of the women discontinued the contraceptive use for no reason, for trivial reason or for menstrual causes. The reasons can be many, which is not the objective of this study.

The newly married women in India during the first year of their marriages should be motivated to use contraceptive methods, which would lead to postponement of their pregnancies. ${ }^{4}$

This can allow the females to prepare themselves physically \& mentally for the forthcoming event of pregnancy \& enjoy a good health. But they do not understand that this is necessary \& very easily achievable.

On interrogating the women about practice of contraception at zero gravidity, only about $3 \%$ revealed history of contraceptive usage before first pregnancy. $96.62 \%$ had never gone for it before first pregnancy as seen in Figure 3. This is consistent with the results of $R$ K Narendra Singh et al who could not find even a single couple going for contraception at this juncture of their reproductive lives. ${ }^{9}$

Sterilization is the most commonly used contraceptive method world-wide. China has the highest number of sterilized population (70 million), followed by India (36 million) in the world. ${ }^{9}$

We observed a mean interval of 1.32 years seen in Table 4 between last childbirth and tubectomy suggesting that those Indian women who choose to have sterilization operation take this decision early after they complete their family size. They are not bothered about properly spacing their pregnancies, but switch over to tubectomy very early.

In our study, the difference between temporary \& permanent contraception was statistically not significant $(\mathrm{p}=0.82)$, suggesting that they use temporary contraception very less, most of them opt for tubectomy soon after the family completion.

When the women who had not completed their families, were counseled for IUCD; they refused it on the basis that they wanted to go for sterilization after one more child and that is why they were not willing for IUCD "at that time". This clearly indicates that most of them have a concept that sterilization is the best way of contraception, concept of spacing is not adapted by most of them.

We found that $71(68.93 \%)$ women did not use any temporary contraception before they opted for sterilization. Only $32(31.06 \%)$ women had practiced temporary contraception in past before they underwent sterilization. In another study almost three fifths of the acceptors $(58.4 \%)$ had not used any contraceptive method prior to accepting sterilization. ${ }^{10}$ One researcher reported a figure of $73.9 \%$ for the same. ${ }^{9}$ From the group of 267 women, $103(38.57 \%)$, underwent sterilization; out of which 102 were female sterilizations and only 1 male sterilization. The reason for this appears to be male dominance in Indian families, where the decision making is done by males \& most of these decisions are taken in favor of the males. The vasectomy percentage goes with that of Nirmala et al $1.14 \%$ (6 vasectomies), but not with tubectomy, which is $51.71 \%$ (271 females). ${ }^{11}$ Vaidyanathan A et al report that female sterilization was preferred by $74.4 \%{ }^{1}$

The medical and paramedical persons were found to have an important role for providing the information of contraception. The medical persons stressed more on spacing the births $(p=0.003)$ whereas the paramedical persons were more inclined to promote sterilization than temporary methods $(\mathrm{p}=0.0001)$. This may be because of the incentive obtained by the motivator for tubectomy.

\section{CONCLUSION}

The contraceptive methods are poorly practiced. In temporary methods, barrier is mostly used. The users do not use any temporary contraception effectively \& adequately. Still they have a false sense of security from unwanted pregnancy. A negligible percentage of eligible women practice contraception before first pregnancy. Very few women practice temporary methods any time before they get sterilization done. Overall, the concept of spacing is lacking. Women are more inclined towards permanent methods. Paramedical workers motivate women for sterilization much more than they do it for temporary methods. Male sterilization is very rarely chosen by the couples.

\section{ACKNOWLEDGEMENTS}

Authors would sincerely thanks to Dr. V. Bhavsar, Dr. A. Athawale for support and guidance extended by them. 
Funding: No funding sources

Conflict of interest: None declared

Ethical approval: The study was approved by the Institutional Ethics Committee

\section{REFERENCES}

1. Vaidyanathan A, Priya CK. Seenivasan P, Malini G, Kaarthika T, Nathan D, et al. A comparative study on the contraceptive methods preferred in the rural \& urban areas in Tamilnadu. Stanley Medical Journal. 2014;1(2):4-8.

2. Leon Speroff. A clinical guide for contraception $5^{\text {th }}$ edition.Philadelphia. Wolters Kluwe. Lippincott Williams \& Wikim. 2011.

3. Ram U. Contraceptive use among young married women in India. International Conference on Family Planning. Uganda, 2009. fpconference.org

4. Srividya V, Kumar J. Family Planning Practices Prior to the Acceptance of Tubectomy: A Study among Women Attending a Maternity Home in Bangalore. India J Clin Diagn Res. 2013;7(8): 1640-13.

5. Thapa S, Rani A, Mishra CP. Knowledge, attitude and belief about contraception in post-partum and post abortal women in a tertiary care centre. Int $\mathbf{J}$ Reprod Contracept Obstet Gynecol. 2014;3(3):5339.

6. Key Indicators for Urban poor in Madhya Pradesh from NFHS-3 and NFHS-2. Assessed Online from 2011.
7. Prachi R, Das GS.A study of Attitude and practice of family planning among the women of reproductive age group in Sikkim. J Obstet GYnnecol India .2008;58(1):63-7.

8. Uma K. A study of the awareness of family planning among the rural population in TamilNadu. International Journal of Scientific \& Engineering Research. 2014;5(2):46-50.

9. Narendra SRK, Ibetombi DT, Bidhumukhi DTH, Anihar SYM, Nonibala DTH, Sharat SN. Ac ceptability of Contraceptive Methods Among Urban Eligible Couples of Imphal, Manipur. Indian Journal of Community Medicine. 2004;29(1):13-7.

10. Dutta PK, Vaz LS, Harinder S. Socio-demographic profile of Tubectomy acceptors-An army experience. The Journal of Family welfare. 1990;36(1):56-60.

11. Lakkawar N, NivedhanaArthi P, Jayavani RL, Shally Magon, Padmaalaganandam. Assessment of knowledge and practice of contraceptives amongwomen in reproductive age attending out patient department at a sub-urban centre in Pondicherry, India Indian Journal of Basic And Applied Medical Research. 2014;4(1):196-209.

Cite this article as: Gadre S, Gadre A. Preferences of eligible women from an Indian medical college hospital for adapting contraceptives. Int J Reprod Contracept Obstet Gynecol 2016;5:35-40. 